\title{
A “INDÚSTRIA" DA INÉRCIA DO CONSUMIDOR
}

\author{
Everton das Neves Gonçalves ${ }^{1}$ \\ Reinaldo Denis Viana Barbosa ${ }^{2}$
}

\section{RESUMO}

Após remissão à responsabilidade civil no Brasil e à exposição de dados de acesso à justiça, o artigo sugere a existência de efetiva "indústria" da inércia do consumidor, representada pelo incentivo à continuidade de violações a direitos, dada a previsibilidade de decisões judiciais, a mitigação do dano moral, além das variáveis do acesso à justiça. $\mathrm{O}$ artigo embasa-se na Análise Econômica do Direito (AED), para a tomada de decisões jurídico-econômicas que desincentivem tal "indústria". Trata-se de pesquisa bibliográfica e documental para a exposição da teoria e dos dados levantados, utilizando o método qualitativo e a análise explicativa.

PALAVRAS-CHAVE: Análise Econômica do Direito. Princípio da Eficiência EconômicoSocial. Direito do Consumidor. Indústria da inércia do Consumidor. Acesso à Justiça.

\section{THE CONSUMER'S INERTIA INDUSTRY}

\begin{abstract}
After a reference to liability in Brazil and to data display access to justice, the article suggests the existence of an "industry" from Consumer inertia, represented by encouraging the continuation of right's violations of law given the predictability of decisions, the moral damage mitigation, in addition to the variables of access to justice. The article is constructed on Economic Analysis of Law (EAL) for the legal and economic decision-making to obstacle that "industry". It's a documentary and bibliographic research for the exhibition of the theory and of the data collected using the qualitative method and explanatory analysis.
\end{abstract}

KEYWORDS: Economic Analysis of Law. Principle of the Economic-Social Efficiency. Consumer Law. The Consumer's inertia industry. Access to Justice.

\section{INTRODUÇÃO}

As relações consumeristas pressupõem a necessidade de dispositivos legais dispostos a aperfeiçoar o mercado de consumo, disciplinando a ação das partes envolvidas tal como definidas no Código de Defesa do Consumidor (CDC). Recentes transformações do Direito

\footnotetext{
* Professor Titular da UFSC. Doutor em Direito Econômico (UFMG/MG); Doctor en Derecho Internacional Económico por la Universidad de Buenos Aires (UBA/ Bs. As.) Argentina; Mestre em Direito (UFSC/SC); Especialista em Comércio Exterior e Integração Econômica no MERCOSUL (FURG/RS); Especialista em Administração Universitária (FURG/RS); Professor credenciado no Programa de Pós-Graduação em Direito da Universidade Federal de Santa Catarina (PPGD/UFSC); Coordenador do Centro de Estudos JurídicoEconômicos e de Gestão para o Desenvolvimento (CEJEGD). E-mail: evertong@ vetorial.net

** Mestrando em Direito pela UFSC, especialista em Direito Penal e Processual Penal pela Escola do Ministério Público de Santa Catarina. Graduado em Direito pelo CESUSC. Advogado. E-mail: reinaldo@advocaciabarbosa.adv.br
} 
contemporâneo resultaram em construções legislativas para a equalização de relações jurídicas marcadas pela desigualdade. As relações individualistas cederam espaço para novos interesses reconhecidos pelo Estado, cujo escopo é corrigir as desigualdades. Violado um direito, nasce o dever de reparar. Essa é uma das máximas da responsabilidade civil. $\mathrm{Na}$ solução das violações levadas ao Poder Judiciário ou, ainda, por formas alternativas, o objetivo é o retorno ao status quo ante, o que pode ser feito por meio de respectiva indenização.

A Análise Econômica do Direito (AED) possibilita lançar “olhar" para além da relação existente entre as partes; objetiva dar previsibilidade aos comportamentos a partir da importação do conceito de eficiência, próprio da Ciência Econômica. Contudo, em tal objetivo não se pode desprezar os reflexos sociais das decisões tomadas, sendo necessária a observação do Princípio da Eficiência Econômico-Social (PEES).

Em que pese a doutrina e a jurisprudência brasileiras referirem-se a uma "indústria" do dano moral, as observações desta pesquisa indicam a existência de outra "indústria": a da inércia do consumidor. Este, tendo um direito violado, decidirá se preferirá a paz ou a resistência à lesão. Os serviços de água, luz, telefone e bancos ocupam o quinto lugar no ranking brasileiro de demandas judiciais. Estas áreas representam exatamente as relações de consumo. De todos os atingidos, o número de pessoas que não buscou solução é três vezes maior do que os mesmos na área trabalhista, responsável pela maior demanda.

Os dados apontam para a necessidade de reflexão sobre as causas e consequências dos danos praticados contra os consumidores, a fim de se saber, se a nossa doutrina e jurisprudência têm andado em sintonia com a proteção Constitucional declarada. Exatamente neste ponto justifica-se esta pesquisa, na medida em que se sugere análise crítica da situação do consumo posta no Brasil.

Quanto ao método de abordagem, dada a necessidade de sistematização da pesquisa e o caminho a ser percorrido, foi utilizado o método dedutivo por considerar análises gerais sobre os elementos conceituais para, então, possibilitar conclusões pontuais. O método de procedimento é o monográfico pela individualização do objeto da pesquisa. Finalmente, quanto à técnica de pesquisa, foi escolhida a bibliográfica, legal, jurisprudencial e documental.

\section{A RESPONSABILIDADE CIVIL NO ORDENAMENTO JURÍDICO BRASILEIRO: A INDÚSTRIA DO DANO MORAL}


A responsabilização civil sempre permeou a pragmática dos diferentes povos. No Código de Hamurabi, por exemplo, já era possível identificar a ideia de responsabilidade e indenização. Em diversos dispositivos desse Código, datado de cerca de 1.600 a C., é possível verificar que o dano sofrido deveria ser indenizado. Rezava o seu Art. 42:

Se alguém tomou um campo para cultivar e no campo não fez crescer trigo, ele deverá ser
convencido que fez trabalhos no campo e deverá fornecer ao proprietário do campo quanto trigo convencido que fez tra
exista no do vizinho ${ }^{3}$.

Nesse contexto de reparação civil, o sociólogo Émile Durkheim (1995, p. 46), ao tratar da solidariedade, assevera que nas sociedades onde haja menor divisão social do trabalho, tem-se solidariedade mecânica. Estas sociedades seriam as mais primitivas, diferindo da sociedade capitalista moderna, na qual se verifica o ápice da divisão social do trabalho, dadas as especialidades. Nesta segunda sociedade, o autor afirma existir solidariedade orgânica. Nas sociedades cuja solidariedade seja mecânica, as relações entre as partes seriam resolvidas, predominantemente, pelo que se conhece, hoje, como Direito Penal; enquanto nas de solidariedade orgânica as reparações seriam civis ${ }^{4}$. Desta forma, a reparação civil como a busca do restabelecimento do status quo ante, esteve presente desde as sociedades mais antigas.

No Direito Brasileiro não há unanimidade doutrinária quanto ao conceito de responsabilidade civil. Para Diniz (2010, p. 34):

\footnotetext{
Poder-se-á definir a responsabilidade civil como a aplicação de medidas que obriguem alguém a reparar dano moral ou patrimonial causado a terceiro em razão de ato do próprio imputado, da pessoa por quem ele responde, ou de fato de coisa ou animal sob sua guarda ou, ainda, de simples imposição legal.
}

Para que a reparação seja possível é necessária a presença dos pressupostos da obrigação de indenizar. Gonçalves (2005, p. 32) identifica-os como uma ação ou omissão, culpa ou dolo do agente, relação de causalidade e o dano experimentado pela vítima ${ }^{5}$. Para ser reconhecida como tal, a conduta deverá contrariar dever geral previsto no ordenamento jurídico, configurando a responsabilidade extracontratual, ou descumprir obrigação assumida, hipótese em que se verificará a responsabilidade contratual.

\footnotetext{
${ }^{3}$ Disponível em http://www.cpihts.com/PDF/C\%C3\%B3digo\%20hamurabi.pdf. Acesso em 04/04/2018.

${ }^{4}$ Inobstante, Ferraz Jr. (2003, p. 215) apresenta pesquisa feita por Tânia Blixen na qual se verificou que para os Kekuyus, no Quênia, característicos de uma sociedade primitiva, todas as violações eram resolvidas pela indenização.

${ }^{5}$ Há divergência doutrinária quanto aos elementos constitutivos da responsabilidade civil. Diniz (2005, p. 42) entende ser esta constituída pela ação ou omissão, dano e nexo de causalidade; Cavalieri Filho (2005, p. 41), por sua vez, identifica como elementos constitutivos a conduta culposa, o nexo de causalidade e o dano.
} 
Importante ressaltar que embora essa seja a concepção geral sobre a ação como pressuposto da responsabilidade civil; qual seja, atuar em desacordo com dever geral legal ou descumprimento de contrato; há situações em que será possível verificar o dever de reparar ainda que o agente não tenha se desvirtuado da legalidade. O parágrafo único do Art. 927 do Código Civil (BRASIL, 2002) prevê essa possibilidade ao afirmar que "haverá obrigação de reparar o dano, independentemente de culpa, nos casos especificados em lei, ou quando a atividade normalmente desenvolvida pelo autor do dano implicar, por sua natureza, risco para os direitos de outrem" 6 .

O legislador está a falar da responsabilidade fundada no risco. Nesses casos, para que nasça o dever de indenizar, não é necessário que o agende se comporte de maneira ilícita. Da mesma forma, nem sempre a sua responsabilidade será limitada ao seu comportamento. Há casos em que será responsável por fato de terceiro ou até mesmo da coisa.

Embora haja situações em que a responsabilidade do causador do dano será verificada independentemente da sua culpa, a responsabilidade subjetiva é a regra no Direito pátrio. A necessidade da verificação do ato ilícito está estampada no próprio Art. 186 do Código Civil ao prescrever que aquele que por ação ou omissão voluntária (dolo), negligência ou imprudência (culpa), causar dano a outrem, deverá repará-lo.

A culpa em sentido amplo, como elemento da responsabilidade civil, compreende o dolo e a culpa em sentido estrito. O dolo é a violação intencional de dever jurídico, enquanto a culpa no sentido estrito refere-se à negligência, à imprudência e à imperícia.

A relação de causalidade é a conexão que deve haver entre a conduta do agente e o dano experimentado. Se houver um dano, mas este não puder ser atribuído ao comportamento do imputado, não haverá responsabilidade civil. Da mesma forma não deverá estar presente qualquer situação que exclua referido nexo de causalidade, como por exemplo, a culpa exclusiva da vítima ou de terceiro, a força maior ou o caso fortuito.

A tutela ressarcitória da pessoa humana compreende não apenas bens físicos, mas a honra, a liberdade, a integridade física, entre outros imateriais. Exatamente nesse ponto reside a grande dificuldade em avaliar a extensão do dano causado à pessoa quando o bem jurídico violado não compõe o seu patrimônio, mas se refere à personalidade.

\footnotetext{
${ }^{6}$ Há outros exemplos no Código Civil. O Art. 931 prevê a responsabilidade dos empresários individuais e empresas pelos danos causados pelos produtos postos em circulação, independentemente de culpa. Na justiça do trabalho brasileira, o empregador deverá indenizar acidente de trabalho sofrido pelo empregado se tiver concorrido para a sua causação, não necessariamente por ato ilícito, conforme o Art. $7^{\circ}$, XXVIII, da Constituição da República Federativa do Brasil de 1988 (CFRB/88).
} 
De todos os pressupostos da responsabilidade civil, o dano é o mais invariável. Isso porque é possível imaginar situações em que a culpa seja relativizada, ou casos em que o sujeito ativo seja uma coisa, mas em qualquer das circunstâncias, será sempre elementar que tenha havido um dano. Cavalieri Filho (2005, p. 95) ensina que "o dano é, sem dúvida, o grande vilão da responsabilidade civil. Não haveria que se falar em indenização, nem em ressarcimento, se não houvesse o dano".

Somente a partir da constatação do dano causado pelo comportamento de agente, desvirtuado do dever geral do ordenamento jurídico, do cumprimento de uma obrigação ou contrato, imputável à sua consciência, seja por dolo ou culpa, é que se formará a relação jurídica que terá o ofendido como credor e o ofensor como devedor.

Considerando que a indenização é o objetivo do lesado, a correta delimitação do dano é indispensável para a sua verificação. Inobstante seja possível a identificação do dano material, moral e estético, todos podendo ser cumulados numa mesma situação, nos termos da Súmula 387 do Superior Tribunal de Justiça (STJ), este trabalho concentrar-se-á apenas no dano moral, por ser indispensável à verificação do problema proposto.

Embora hoje a ideia de dano moral esteja no senso comum, nem sempre foi assim. A realidade era sensivelmente diferente antes do Código Civil de 1916 e principalmente da $\mathrm{CRFB} / 88$. Os incisos $\mathrm{V}$ e $\mathrm{X}$ do Art. $5^{\circ}$ da Constituição vigente não dão margem a qualquer dúvida sobre a preocupação do legislador constituinte em tutelar a subjetividade dos indivíduos. A importância é perceptível, ainda, pela localização topográfica dos dispositivos, dispostos no Capítulo destinado aos Direitos e Garantias Fundamentais.

Diniz (2010, p. 90) conceitua o dano moral como sendo "a lesão de interesses não patrimoniais da pessoa natural ou jurídica, provocada pelo fato lesivo.” A utilização da expressão "interesse" é bastante facilitadora para a compreensão da extensão do dano extrapatrimonial. É por esse critério; interesse, que se deve passar a análise do dano moral. De fato, toda lesão a direito repercute no interesse. Um dano a bem extrapatrimonial, como a saúde, por exemplo, pode resultar em prejuízos materiais (despesas com tratamento, danos emergentes e lucros cessantes pela incapacidade para o trabalho), mas, da mesma forma, há um interesse à incolumidade física que pode ser afetado pela ação danosa.

No mesmo exemplo citado acima, se a lesão resultar em deformidade física, que afete a estética, provocando baixa autoestima da vítima, terá lugar junto ao dano material, o dano moral. Da mesma forma, assumindo o caminho inverso, é possível verificar a existência 
de dano patrimonial indireto que resulte de ofensa direta a bem extrapatrimonial. Exemplo disso é o caso em que determinado comerciante é injuriado e em decorrência disso as vendas diminuem. Nesta situação, o dano que teve origem na subjetividade refletirá danos patrimoniais. Destarte, o critério para a verificação do dano não pode ser a sua natureza, se patrimonial ou extrapatrimonial, mas os efeitos da lesão.

A grande confusão que se faz sobre a percepção do dano moral reside exatamente na tentativa de identificar a dor, o sofrimento, e outros sentimentos experimentados pela vítima. Por certo seria tarefa para a qual o profissional do Direito não estaria habilitado, nem mesmo considerando a multidisciplinariedade. Não há como medir sentimentos. A morte violenta de uma mãe, v.g., gera dor de diferentes proporções nos filhos. Nesse sentido Andrade (2006, p. 68) afirma que:

\footnotetext{
O dano será a lesão em si, a algum direito da personalidade, não será a lágrima derramada em decorrência dessa lesão. Melhor seria dizer que o dano moral não se reduz à dor e a outras sensações ou sentimentos negativos. Tais reações, quando presentes, integram o dano moral, embora não sejam essenciais a ele.
}

Por isso pessoas não são indenizadas pela morte cruel de um detento do sistema prisional, ainda que fiquem profundamente abalas. Mas somente poderão ser indenizadas as pessoas que tiveram um interesse violado, como o filho privado da convivência do pai por conta da falha na segurança do presídio. A estes deverá haver reparação não na medida da dor experimentada, mas suficiente a atenuar as consequências da lesão sofrida. Esse entendimento permite superar um dos maiores dilemas sobre o dano moral, que é a sua monetarização. De fato haveria bastante dificuldade se a tarefa fosse atribuir valor monetário a uma perda, a angústia, dor, ou qualquer sentimento. Mas não se entende deva ser essa a concepção do dano moral. A necessidade da reparação surge da violação de interesse juridicamente protegido. Contudo, o valor pecuniário atribuído não se presta a compensar tal violação, posto que impossível. Diferentemente, objetiva a proporcionar a atenuação dos prejuízos que sofreu, proporcionando-lhe alguma distração ou bem-estar.

A rigor, nem mesmo os danos patrimoniais podem ser reparados na exata proporção da lesão, isso porque a simples substituição de um bem destruído não compensa integralmente a perda, uma vez que a vítima não desejaria tê-la e, por isso, a restituição do patrimônio não faz com que o lesado sinta-se compensado.

A doutrina tem se ocupado em apresentar diversos critérios para orientar o juiz na fixação do quantum indenizatório. Diniz (2010, p. 105), por exemplo, apresenta os seguintes critérios: a) evitar indenização simbólica e enriquecimento sem justa causa, ilícito ou injusto 
da vítima; b) não aceitar tarifação; c) considerar a gravidade, extensão e natureza da lesão; d) verificar a repercussão pública do fato lesivo; e) atentar para as peculiaridades do caso e o caráter antissocial da conduta lesiva; f) averiguar, além dos benefícios obtidos pelo lesante, a sua atitude ulterior e situação econômica; g) apurar o valor real do prejuízo e o lucro cessante; h) levar em conta o contexto econômico do país; i) levar em consideração as posses econômicas do ofensor; j) basear-se em prova firme e convincente do dano; k) analisar a intensidade do sofrimento; 1) procurar a harmonização das reparações em casos semelhantes; m) demonstrar para a sociedade que a conduta lesiva é condenável.

Nem todos os critérios acima são pacificamente aceitos. Os critérios ficam mais perigosos quanto mais subjetivos se tornam. Analisar a intensidade do sofrimento é tarefa dificílima (se não impossível); apurar o valor real do prejuízo e o lucro cessante se confunde com o dano material; basear-se na prova da lesão é tão difícil quanto avaliar a dimensão do sofrimento. Ao invés disso, a prova apurada deve ser a da ofensa ao interesse juridicamente protegido.

É pressuposto da responsabilidade civil a existência de ato ilícito e dano que decorra dele. Sendo assim, não é razoável que, na análise do caso concreto, o juiz identifique tais elementos, entendendo cabível a indenização e; no entanto, faça menção a enriquecimento sem causa. Necessário esclarecer que a expressão "enriquecimento" não faz referência à mudança de camada social. Diferentemente disso, o legislador chama a atenção para qualquer acréscimo patrimonial desapegado de justa causa. Desta forma, é contraditório reconhecer a existência da motivação da indenização, mas utilizar a vedação ao enriquecimento sem causa para fixar o seu valor. Ou há justa causa para a reparação ou não há. As duas sentenças não são comportadas num mesmo caso.

Há quem entenda "enriquecimento sem causa" como o acréscimo patrimonial além do dano sofrido. Contudo, pela utilização desse critério, considerando que o dano moral é violação de interesse extrapatrimonial que deverá ser compensada no campo patrimonial, todos os casos de indenização inevitavelmente serão casos de enriquecimento sem causa.

Existe relevante discussão doutrinária e jurisprudencial sobre a importação do punitive damages ao Direito brasileiro. Tal instituto representa a condenação da parte ré em ação indenizatória ao pagamento de valor superior ao que seria a extensão do dano causado, a fim de que a condenação alcance as finalidades de punição e prevenção. 
Nos Estados Unidos da América (EUA), o caso emblemático da BMW of North America, Inc. v. Gore (1996) foi fundamental para a delimitação naquele País dos critérios de aplicação dos punitive damages. Nesse caso, a BMW of North America havia repintado uma parte do veículo a fim de esconder um dano. O júri condenou a ré a pagar US\$4.000 pela diminuição do valor do carro e US\$4.000.000 a título de compensatory damages. Após recorrer à Suprema Corte do Alabama e à dos EUA, a indenização foi reduzida para US\$50.000. A partir desse caso, fixaram-se três "balizas" para a definição dos punitive damages: o grau de reprovabilidade da conduta do réu; a disparidade entre o dano efetivo ou potencial sofrido pelo autor e os punitive damages; a diferença entre os punitive damages concedidos pelo júri e as multas civis autorizadas ou impostas em casos semelhantes.

No Brasil, a legislação ainda mostra reticência quanto à importação do instituto. $\mathrm{O}$ Projeto de Lei 6960/2002, atualmente arquivado, tentou acrescentar ao Art. 944 do Código Civil o seguinte parágrafo: "§ $2^{\circ}$ A reparação do dano moral deve constituir-se em compensação ao lesado e adequado desestímulo ao lesante".

Da mesma forma, o Código de Defesa do Consumidor ensaiou a regulamentação dos punitive damages ${ }^{7}$, o que foi vetado pelo Presidente da República sob o argumento de que o Art. 12 já dispunha de modo suficiente sobre o dano sofrido pelo consumidor. Além de que os dispositivos vetados criariam a figura da multa civil, sem que fossem definidas a sua destinação e finalidade.

Ainda que não se admita a utilização dos punitive damages no Ordenamento Jurídico brasileiro, o próprio sistema tem ferramentas aptas a servirem de desestímulo à prática lesiva. Exemplo disso é a Lei $n^{\circ} 7247 / 85$, que regulamenta a Ação Civil Pública, possibilitando a responsabilização, punitiva, por danos causados ao consumidor.

Contudo, o Judiciário tem utilizado o caráter punitivo do dano moral apenas secundariamente. Isso pelo fato de que depois de fazer referência à função pedagógica da indenização, tem afirmado não poder ser, a mesma, alta a ponto de enriquecer o autor indevidamente. Nesse sentido, Oliveira (2005, p. 177-178):

\footnotetext{
${ }^{7}$ Os dispositivos vetados foram os seguintes: "Art. 16 - Se comprovada a alta periculosidade do produto ou do serviço que provocou o dano, ou grave imprudência, negligência ou imperícia do fornecedor, será devida multa civil de até um milhão de vezes o Bônus do Tesouro Nacional - BTN, ou Índice equivalente que venha substituí-lo, na ação proposta por qualquer dos legitimados à defesa do consumidor em juízo, a critério do juiz, de acordo com a gravidade e proporção do dano, bem como a situação econômica do responsável." "Art. 45 - As infrações ao disposto neste Capítulo, além de perdas e danos, indenização por danos morais, perda dos juros e outras sanções cabíveis, ficam sujeitas à multa de natureza civil, proporcional à gravidade da infração e à condição econômica do infrator, cominada pelo juiz na ação proposta por qualquer dos legitimados à defesa do consumidor em juízo." Art. $52-" \S 3^{\circ}$ - O fornecedor ficará sujeito a multa civil e perda dos juros, além de outras sanções cabíveis, se descumprir o disposto neste artigo".
} 
Fato interessante é a existência de julgados que, ao mesmo tempo que reconhecem o caráter punitivo do dano moral vedam o enriquecimento por parte do lesado. Ocorre que, nestes casos, o enriquecimento do lesado é consequência inevitável, visto que receberá, além da compensação dos danos sofridos, quantia representativa dos danos punitivos.

Santos (2003, p. 204) retrata o entendimento, em geral, dos Tribunais pátrios a respeito:

\footnotetext{
A reparação de um dano moral, seja qual for sua espécie, não deve significar uma mudança de vida para a vítima ou para a sua família. Uma fonte de enriquecimento surgida da indenização. O dano moral não pode servir a que vítimas ou pseudovítimas vejam sempre a possibilidade de ganhar um dinheiro a mais, enriquecendo-se diante de qualquer abespinhamento.
}

A posição referida requer cuidados para com as partes que propõe ações indenizatórias ao pressupor a existência de pseudovítimas buscando "ganhar um dinheiro a mais". Estes infelizes argumentos têm tido espaço nas decisões judiciais. Na verdade o que se pretende é desestimular ações reparatórias. Nesse sentido, Cavalieri Filho (2008, p. 239):

\footnotetext{
Fala-se hoje numa indústria da responsabilidade civil, com o que não concordamos. Não há indústria sem matéria-prima, de sorte que se hoje os casos judiciais envolvendo responsabilidade
} civil são tão numerosos é porque ainda mais numerosos são os casos de danos injustos.

Desta forma, visando coibir dita "indústria do dano moral", os Tribunais deixam de aplicar o caráter punitivo na condenação - embora utilizem esse critério na fundamentação. Isso acaba submetendo os autores a dupla vitimização: primeiramente pela conduta lesiva e, em segundo plano, pelo próprio Órgão jurisdicional que, por questão de política judiciária, priva-os dos critérios necessários para a fixação do quantum indenizatório. Decisões com esse fundamento reconhecem como aceitável o comportamento lesivo. Imaginando-se dado Banco, por exemplo, em que se cobra indevidamente dada tarifa de todos os seus correntistas e, aos poucos que reclamem judicialmente, ainda serem-lhes negados os pedidos por questão de política judiciária, ou mesmo que julgados procedentes os pedidos, estes sejam atendidos minimamente para que não se enriqueça ilicitamente o autor, não haveria nenhum desestímulo para o comportamento lesivo perpetuado pelo referido Banco.

Afinal, condenar dito Banco a pagar $\mathrm{R} \$ 10.000,00$ por danos morais em função de cobrança indevida de centavos é absurdo. Contudo, a interpretação aplicada ao caso deve ser a da Análise Econômica do Direito (AED), que permite a utilização de "olhar" multidisciplinar que não esteja limitado à objetividade do caso concreto. Chamando a atenção para a importância das decisões judiciais na previsibilidade do comportamento humano, Richard Allen Posner (2007, p. 59) ressalta que "a decisão é uma prevenção no sentido de que se nos comportarmos de certo modo e se produz um acidente, teremos que pagar uma compensação".

Importante, então pensar as indenizações por danos morais a partir da AED. 


\section{ANÁLISE ECONÔMICA DO DIREITO E O PRINCÍPIO DA EFICIÊNCIA ECONÔMICO-SOCIAL (PEES)}

A vida em sociedade é marcada pela necessidade de tomada de decisões e escolhas, dada a escassez dos recursos disponíveis. Justamente em decorrência da vida coletiva, as decisões tomadas quase sempre afetam outras pessoas. A grande questão na Civil Law passa a ser a identificação dos interesses que devem ser protegidos por lei e, dentre estes, quais devem ser sacrificados em detrimento de outros. Há diversos critérios de justiça disponíveis para solucionar os problemas decorrentes dessa necessidade de tomada de decisão e sua repercussão jurídico-econômico-social, como a justiça restaurativa, distributiva, comutativa e retributiva. Pra além de tais critérios, a Law and Economics (LaE) apresenta-se como opção de política jurídica apta a "analisar o problema jurídico segundo método próprio ao exercício da vontade" (GONÇALVES e STELZER; 2005, p. 202).

A interação entre Direito e Economia surgiu nos EUA, na década de 60, sendo os seus pioneiros, o economista Ronald H. Coase em The problem of social cost (1960) e Guido Calabresi com Some Thoughts on Risk Distribution and the Laws of Torts (1961).

Até então tida como movimento, a AED adquiriu notável expressão no início da década de 70 com Richard Allen Posner que tratou de aplicar a Teoria Econômica na análise de diversos ramos do Direito, como Direito de Propriedade, Penal, Constitucional, Família, entre outros. A LaE propõe-se, portanto, a verificar a racionalidade econômica do próprio Direito, proporcionando recurso metodológico conhecido que evite a escolha de critérios de justiça aleatórios.

Por considerar que a LaE é, na verdade, critério de justiça destinado a resolver problemas dentro do contexto socioeconômico sem recorrer a fórmulas outras que não a racionalidade intrínseca ao meio em que ocorrem os questionamentos e segundo argumentação lógico-racional e critério único e conhecido de todos, Gonçalves e Stelzer (2005, p. 202) entendem que a Teoria Econômica exerce papel normativo e positivo no estudo dos institutos da Civil Law.

A análise do Direito a partir da Ciência Econômica, como proposta por Coase, considera a necessidade de se fazer operações de custo e benefício das decisões a serem tomadas, considerando que estas terão consequências. Desta forma, à escassez dos recursos e à necessidade dos indivíduos, deve ser acrescentada referida ponderação. 
Em The problem of social cost, Coase critica o trabalho de Arthur Cecil Pigou intitulado The Economic of Welfare, publicado em 1920. Refutando a abordagem tradicional da análise de situação na qual um indivíduo causa prejuízo a outro, Coase afirma que a questão não é impedir que uma das partes cause referido prejuízo. Diferentemente, a análise deve ser recíproca, na medida em que a adjudicação do direito de um deles automaticamente resulta na causação de prejuízo ao outro.

Desta forma, a questão deve ser analisada sob a perspectiva de qual das partes deve ser autorizada a causar prejuízo à outra, passando o problema a ser evitar o prejuízo mais grave, em perspectiva de reciprocidade de interesses.

No caso Sturges v Bridgman citado na sua obra, Coase fala de um confeiteiro que, ao utilizar o seu maquinário, causava perturbação a um médico que ocupava o prédio vizinho, impedindo-o de utilizar adequadamente uma de suas salas de consulta. Pela análise tradicional da Common Law, o questionamento seria: como impedir que o confeiteiro causasse dano ao médico? Diversamente, Coase sugere que, para a eficiente tomada da decisão, deveria haver uma barganha entre os envolvidos que considerasse, socialmente, o valor do que é obtido e o valor daquilo que é sacrificado para obtê-lo. Isso porque há casos em que os custos para se conquistar um objeto são tão elevados que desestimulam a sua persecução; em outros, os benefícios gerados pela conquista são tão altos que compensam os sacrifícios realizados.

No caso citado, o Tribunal garantiu ao médico o direito de impedir o confeiteiro de utilizar o seu maquinário. Contudo, a situação poderia ter sido resolvida por meio de barganha entre as partes: o médico estaria satisfeito se o confeiteiro pagasse para ele valor maior do que a perda de renda pela não utilização da sala, pela mudança para outro local ou pela construção de outra parede que abafasse os ruídos e vibrações dos equipamentos. O confeiteiro estaria disposto a pagar desde que o valor fosse menor do que a queda na renda que ele sofreria pela mudança no modo de operação ou por se mudar para outro local. A solução, desta forma, está em saber se a utilização do maquinário acrescenta mais renda ao confeiteiro do que diminui do médico. (COASE, 1960, p. 1-44)

Considerando a existência de externalidades que impedem o mercado perfeito, estas podem ser resolvidas a partir das ponderações acima referidas, desde que os custos de transação sejam inexistentes ou irrisórios, diferentemente do pensamento de Pigou ${ }^{8}$. Assim,

\footnotetext{
${ }^{8}$ Para Pigou ocorreria falha de mercado sempre que os custos privados e sociais e benefícios privados e sociais não tivessem em equilíbrio, o que resultaria em uma incorreta alocação de recursos.
} 
conforme a proposta de Coase, na situação em que os custos das transações sejam zero ou desconsideráveis, não importa para quem o direito será adjudicado.

Em 1909, Vilfredo Pareto publicou o Manuale di economia politica con una introduzione alla scienza sociale, do qual é possível extrair duas críticas à Teoria da Utilidade tradicional ${ }^{9}$ pela impossibilidade de comparação entre sentimentos e sensações diferentes. A primeira delas estava no fato de que tal comparação ignorava a existência de diferenças e conflitos na sociedade. Há situações em que é irracional colocar o bem-estar de pessoas em conflito numa mesma equação. Pareto (1909, p. 62), exemplificando, assevera que:

[...] a felicidade dos romanos reside na destruição de Cartago; a felicidade dos cartagineses talvez na destruição de Roma, ou, de qualquer forma, na salvação de sua cidade. Como ambas, a felicidade dos romanos e a dos cartagineses, podem ser realizadas?

A segunda crítica residia no fato de a equação permitir comparações de conteúdo moral duvidoso em casos nos quais a satisfação de alguém dependa do sofrimento de outro. Pareto, então, questiona se a escravidão é moral ou não. Se considerar uma sociedade na qual os senhores são numerosos e os escravos são poucos, é possível que o bem-estar dos senhores forme soma maior do que as sensações de sofrimento dos escravos. Contudo, se os escravos são muitos e poucos os senhores, ocorreria o inverso (PARETO, 1909, p. 63). No primeiro caso, o fim da escravidão importaria em diminuição do bem-estar da sociedade.

Desta forma, questionando a possibilidade tradicional de comparações interpessoais de utilidade, Pareto introduz o conceito ordinal de bem-estar social, segundo o qual somente seriam possíveis as comparações entre situações cuja mudança de uma para outra não resultasse em transferência de utilidade $^{10}$. Dois conceitos foram desenvolvidos: a Superioridade de Pareto e o Ótimo de Pareto. Pelo primeiro conceito, o bem-estar associado a uma situação X é maior do que o bem-estar associado a uma situação Y se, em X, há pelo menos um indivíduo com bem-estar maior do que o de Y e não há outro indivíduo que tenha

\footnotetext{
${ }^{9}$ A função da Utilidade para a economia tradicional era apresentada pela mensuração da quantidade de utilidade em escala numérica. Sendo assim, seria possível a comparação de bem-estar entre dois ou mais indivíduos, bem como a agregação de utilidades individuais. Para aprofundar o estudo, ler WALRAS, L. em Compêndio dos Elementos de Economia Política Pura. São Paulo, Editora Nova Cultural, 1996.

${ }^{10}$ Sobre a crítica à utilização do conceito de bem-estar pelos clássicos, ver SCITOVSZKY, Tibor de. A note on welfare propositions in economics. The review of economic studies, v. 9, n. 1, p. 77-88, 1941. Disponível em: <http://www.hujingbei.net/upload/2007_11/07110714376633.pdf>. Acesso em: 04/04/2018. O autor esclarece a diferenciação que há na Teoria Econômica entre a economia positiva, preocupada com o funcionamento do sistema econômico, e a economia do bem-estar social, servindo de prescrição à política. Este segundo viés, cujo objetivo é testar a eficiência das instituições econômicas em fazer uso dos recursos produtivos em comunidade foi deixado em segundo plano pela impossibilidade de comparação interpessoal. Os recursos produtivos eram vistos pelos clássicos como de quantidade fixa, sendo a eficiência verificada a partir da capacidade de alocar recursos numa comunidade fechada de pleno emprego, de concorrência perfeita e livre comércio. Desta forma, para verificar a eficiência, as taxas de substituição dos produtos eram consideradas iguais em todos os lugares e para todas as pessoas. Somente assim seria possível identificar o ponto máximo de elevação da satisfação de uma pessoa sem que importasse em diminuição da de outra pessoa.
} 
nível de bem-estar inferior; ou seja, o bem-estar será superior se for possível aumentar o bemestar de pelo menos um indivíduo sem prejudicar os demais.

Disso resulta o Ótimo de Pareto, situação na qual o bem-estar será máximo quando não for mais possível aumentar o bem-estar de um indivíduo sem diminuir o dos demais. $\mathrm{O}$ critério utilizado por Pareto para identificar a situação ideal de adjudicação de direito se torna pouco prático pela dificuldade de se encontrar o ponto de equilíbrio no qual as partes envolvidas deixarão de realizar trocas voluntárias devido ao atingimento da melhor situação possível para todos.

Em 1939, dois autores surgiram no cenário da delimitação do conceito de eficiência a partir da análise do bem-estar. Nicholas Kaldor e John Hicks desenvolveram teorias que mais adiante ficaram conhecidas como o critério Kaldor-Hicks. Para dito critério é possível que, atingido o Ótimo de Pareto, ainda se encontre possibilidade de mudança social eficiente, desde que a parte cujo bem-estar sofreu redução possa ser compensada.

Partindo do pressuposto de que nas relações sociais sempre há ganhadores e perdedores, Kaldor e Hicks desenvolveram critério que, aproximando-se da realidade, permitisse que a busca da eficiência não se limitasse à imaginária situação de equilíbrio do bem-estar dos envolvidos. Avançando no conceito, os autores conceberam que um estado de coisas $\mathrm{X}$ é eficiente em relação a outro estado $\mathrm{Y}$, se, depois da mudança do estado $\mathrm{X}$ para $\mathrm{O}$ estado $\mathrm{Y}$, a valorização da nova posição de $\mathrm{X}$ é maior do que o prejuízo de $\mathrm{Y}$.

Os critérios de eficiência de Pareto e de Kaldor e Hicks não enfatizaram as externalidades sociais envolvidas nas transações, o que permitiu que Gonçalves e Stelzer (2014, p. 269) desenvolvessem o Princípio da Eficiência Econômico-Social (PEES). Defendendo a utilização de "visão" multi e interdisciplinar do Direito enquanto disciplinador das relações sociais, os autores identificaram a contribuição da Ciência Econômica - como ciência analítica por natureza - na persecução desse objetivo na medida em que:

\footnotetext{
proporciona a metodologia necessária para quantificar interesses, analisar procedimentos e indicar soluções com tendências probabilísticas que levem à dissipação de conflitos e à satisfação das necessidades, bem como à elaboração legislativa.
}

Segundo os autores, o modelo jurídico-legal, sob o prisma da Análise Econômica do Direito, "volta-se para o futuro de forma a influir a ação dos indivíduos através de conjunto de incentivos e obstáculos.” (GONÇALVES e STELZER 2014, p. 268). A conclusão apontada encontra supedâneo em Posner (2007, p. 25) ao afirmar que o homem procura sempre de forma racional aumentar ao máximo o que chama de interés proprio. 
Por critério outro de justiça, o cometimento de ato ilícito que cause dano moral ao consumidor, $v . g$., seria solucionado pelo Direito com a compensação da dor provocada, na impossibilidade de retorno ao status quo ante. A proposta da AED é a de um "olhar" para o futuro de forma a interferir nas ações dos indivíduos por meio de conjunto de incentivos e obstáculos. Por esse viés, o Direito passa a influenciar o comportamento social pela análise da relação custo e benefício.

O PEES propõe, assim, nova interação entre Direito e Economia para persecução da eficiência. Contudo, devem necessariamente ser consideradas, no cálculo econométrico, as externalidades sociais. Segundo Gonçalves e Stelzer (2013, p. 141):

\footnotetext{
Trata-se da elaboração e aplicação da norma de forma economicamente eficiente, maximizandose resultados esperados quando da adjudicação de direitos ou da determinação de obrigações, conforme caráter recíproco das ações e interesses, porém, considerando o reflexo social e o custo externo imposto à sociedade presente; ou mesmo, futura, de forma a serem compensadas, na totalidade, os prejuízos impostos pelo ganho presente das partes envolvidas.
}

Pelo PEES, a distributividade, a justiça social, a defesa do meio ambiente, a erradicação do desemprego, dentre outros fatores com reflexos sociais devem ser internalizados e equacionados na análise econômica a ser feita pelo legislador e pelo operador do Direito. (GONÇALVES e STELZER, 2007, p. 7).

Exposta a questão da necessária responsabilização civil no Ordenamento Jurídico brasileiro e a possibilidade de abordagem econômico-jurídica da mesma, resta destacar o problema da "indústria do dano moral" que surge em torno dela pelo olhar proposto pela AED.

\section{A "INDÚSTRIA" DA INÉRCIA DO CONSUMIDOR}

Em 2011, o Conselho Nacional de Justiça (CNJ) divulgou o Panorama do Acesso à Justiça no Brasil, 2004 a 2009. O levantamento compôs o suplemento sobre Vitimização e Acesso à Justiça da Pesquisa Nacional por Amostra de Domicílios (PNAD) de 2009, do Instituto Brasileiro de Geografia e Estatística (IBGE).

O suplemento é bastante esclarecedor quanto aos tipos de conflitos mais graves ${ }^{11}$ vividos pelos brasileiros no período de 2004 a 2009, a via escolhida para solucioná-los, se foram de fato solucionados e, além de outros dados, o que mais interessa para este trabalho: os casos em que não se buscou solução.

O primeiro Gráfico (1) apresentado mostra-nos as áreas de conflito.

\footnotetext{
${ }^{11}$ Os entrevistados eram orientados a apontar apenas um dos conflitos vividos no período, o mais grave, segundo o seu julgamento.
} 
Panorama do acesso ả justiça no Brasil, 2004 a 2009

Gráfico 1 - Percentagem de pessoas que vivenciaram conflitos entre 2004 e 2009 segundo a área da situação de conflito e a busca de soluções para ele, Brasil, $2009^{4}$.

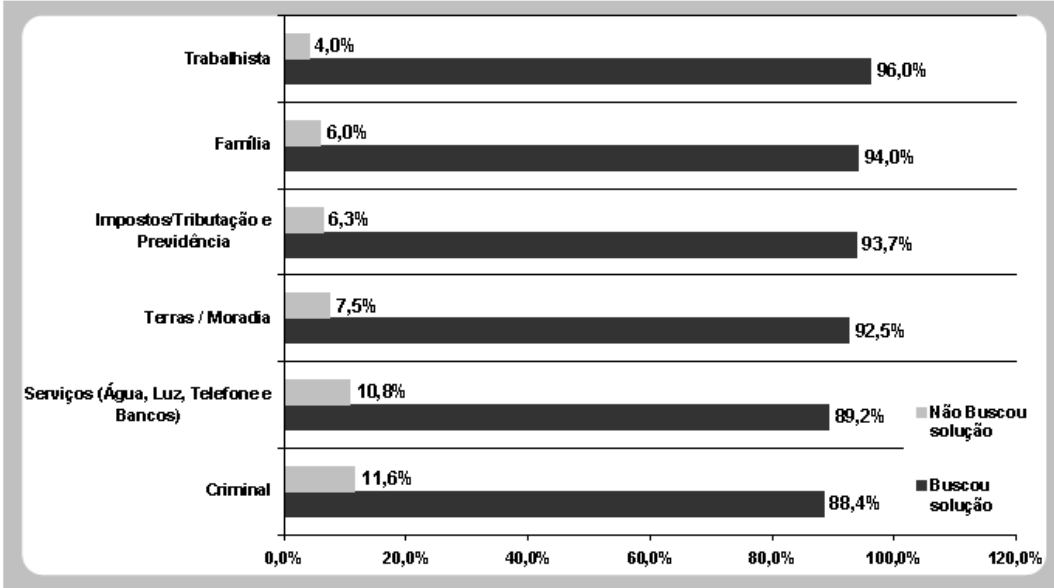

Fonte: CNJ.

As áreas; trabalhista; família; impostos, tributação e previdência ocupam os três primeiros lugares na lista dos conflitos vividos pela população. As relações de consumo, representadas pelos setores de fornecimento de água, luz, telefone e bancos estão em quinto lugar. Contudo, o que chama a atenção é a quantidade de pessoas que não buscaram solução.

Em uma primeira vista, pode parecer um número razoável 10,8\% das pessoas que se julgaram lesadas nas relações de consumo não terem procurado a resolução do conflito. Contudo, quando comparado às demandas trabalhistas, por exemplo, é possível notar que a quantidade de pessoas desalentadas nas relações de consumo é quase três vezes maior do que nas trabalhistas. Essa constatação é também percebida no Gráfico (2) a seguir.

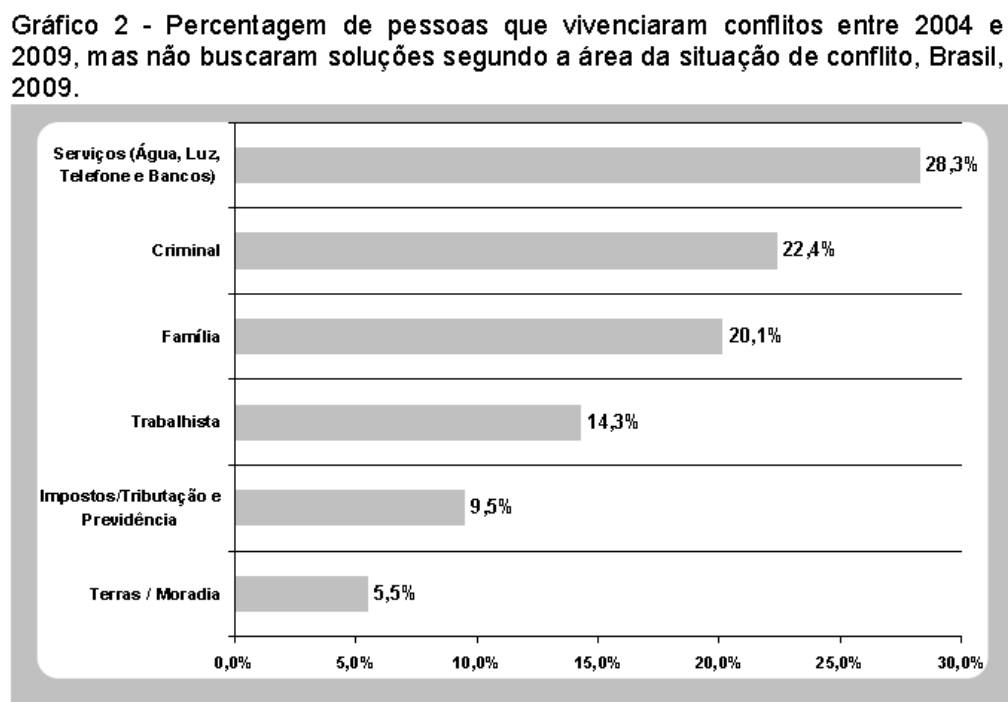

Fonte: CNJ 
Um dos motivos apresentados no levantamento para justificar o elevado número de casos nas relações consumeristas em que não se buscou a solução dos conflitos é a grande probabilidade de que o custo da solução seja mais alto do que o dano em si, ainda que considerado eventual valor pago a título indenizatório.

A análise representa a conclusão de Coase (1960, p. 8-15) de que quando os custos da transação são zero ou desconsideráveis, tanto faz para quem o direito será adjudicado, uma vez que o resultado eficiente poderá ser obtido pela barganha entre as partes de modo a internalizarem-se as externalidades. Desta forma, o consumidor lesado apenas se sentiria seguro em buscar solução se a expectativa de satisfação fosse maior do que os custos para implementá-la.

Ainda que se reconheça a existência de defensorias públicas e núcleos privados que se destinem a atender à população necessitada, outro Gráfico (3) aponta para a realidade de que a renda das pessoas lesadas é fator decisivo na busca de solução.

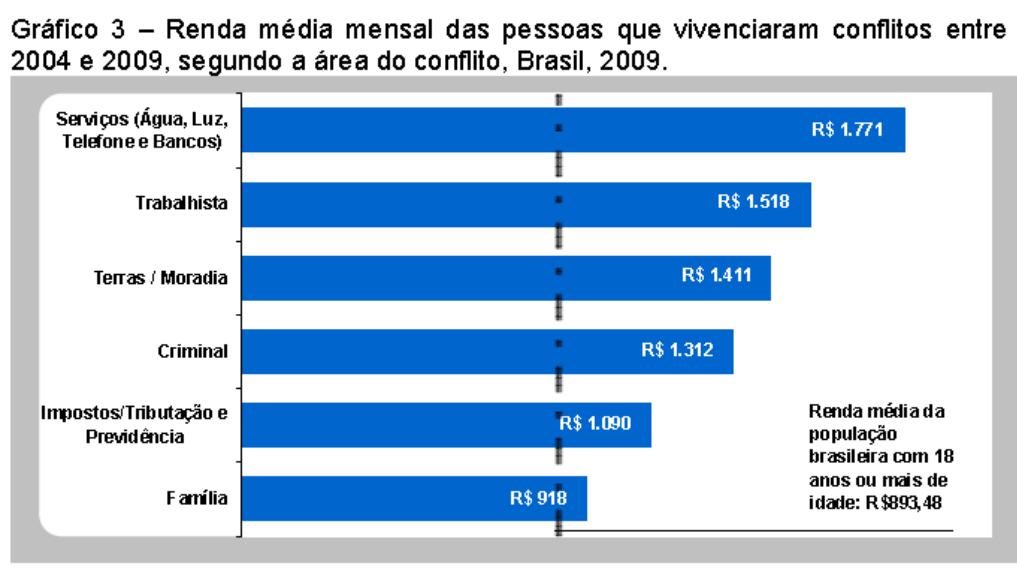

Fonte: CNJ

Considerando a renda média das pessoas que vivenciaram conflitos nas relações de consumo como sendo maior do que em todas as outras e que o maior número de pessoas que não procuraram solução foi exatamente nessa área, é possível concluir que o motivo justificador de tais dados seja o custo das transações. Em outras palavras, é dizer que o conflito em jogo é pequeno se comparado ao rendimento do lesado.

Imagine-se a seguinte situação: no mês de maio de 2018 o cliente "A" da operadora de telefone "Sinal Total" decide finalizar o seu contrato, cancelando o plano mensal cujo valor era de $\mathrm{R} \$ 100,00$. “A” manifesta a sua intenção no canal de atendimento e lhe é informado que pagará o consumo proporcional até o momento da rescisão. 
Ocorre que nos meses de abril e maio de 2018 a "Sinal Total" enviou duas faturas para a residência de "A" com os valores integrais das mensalidades do plano. Junto às faturas vieram diversas ligações diárias para o seu celular, casa e trabalho, cobrando o pagamento das faturas.

“A" explica o ocorrido e apresenta o número do protocolo da ligação de cancelamento do plano e a atendente afirma que se tratou de um mal entendido e pede que desconsidere as faturas.

Contudo, no mês de julho "A" recebe notificação informando que o seu nome foi inscrito no cadastro de inadimplentes pelo não pagamento das faturas de abril e maio. Nesse momento "A" poderá tomar uma das seguintes providências: i) enfrentar longas ligações para tentar explicar novamente que a cobrança é indevida e solicitar a exclusão do registro administrativamente; ii) propor ação de reparação pelos danos extrapatrimoniais gerados pela cobrança indevida e pela inscrição do nome no cadastro de inadimplentes; iii) pagar a dívida, embora indevida, para evitar maiores transtornos.

Para a primeira opção "A" deverá dispor de recursos bastante limitados: tempo e paciência. Já com relação à segunda opção, deverá ponderar o valor da cobrança e o valor que seria gasto para a propositura da ação. Nesse momento, ao comparar os $\mathbf{R} \$ 200,00$ cobrados indevidamente com o desconforto da litigância, os custos com honorários advocatícios e processuais, "A" acabará sendo "empurrado" para a terceira opção. Nesse sentido, explica Ihering (1872, p. 65):

Quando um indivíduo é lesado em seu direito, faz-se irremissivelmente esta consideração, nascida da
questão que em sua consciência se apresenta, e que pode resolver como bem lhe aprouver: - se deve
resistir ao adversário ou se deve ceder. Qualquer que seja a solução, deverá fazer sempre um sacrifício; -
ou sacrificará o direito à paz ou a paz ao direito.

Se a análise custo-benefício para a tomada de decisão é feita mesmo na simplicidade do cidadão comum, imagine-se em superempresas! Seria ingenuidade acreditar que as cobranças indevidas, quantidade de reclamações, quantidades de condenações, valor da condenação, duração do processo, e outros fatores não são precisamente acompanhados pelas instituições. Não bastassem os custos da transação, por vezes os consumidores são desestimulados pelo próprio Poder Judiciário que insiste em considerar diversas situações como "meros aborrecimentos do dia a dia". Decisões com essa justificativa são cada vez mais frequentes e impedem que as empresas ofensoras modifiquem a forma como prestam os seus serviços. 
Caso emblemático para compreender essa análise das instituições é o do "Ford Pinto". Surgiu nos Estados Unidos, no final da década de 60, demanda por carros compactos devido à falta de combustível e ao crescimento do setor automobilístico. A proposta de solução para a crise, adotada pela Ford, foi o "Ford Pinto". Para a sua fabricação estabeleceuse que não deveria pesar mais de 2.000 libras e não deveria custar mais de U\$2.000 para fabricação. A segurança não era uma das preocupações da empresa, que ignorou os resultados dos testes de colisão que apontavam para a necessidade de melhoria na proteção do tanque de combustível. Nos testes, verificou-se que o tanque de combustível era danificado mesmo em colisão a 40,23 Km/h. Destarte, logo começaram os acidentes decorrentes da falta de segurança. Diante da situação a Ford teve duas alternativas: fornecer solução para cada carro vendido (recall) ou indenizar as vítimas nos eventuais processos.

Os dados para a tomada de decisão eram os seguintes: i) os tanques inseguros causariam 180 mortes por queimadura por ano; ii) 180 ferimentos graves por queimadura por ano; iii) 2.100 veículos queimados por ano; iv) \$ 200.000 de indenização por morte; v) \$ 67.000 por ferimento; vi) $\$ 700$ por veículo danificado. Tudo isso resultaria em um total de 49,5 milhões de dólares. Em contrapartida, para garantir a segurança de toda a frota vendida, a empresa gastaria $\$ 11,00$ por veículo, resultando em 137 milhões de dólares ${ }^{12}$.

Em 1972, enquanto conduzia um Ford Pinto, Lily Gray e Richard Grimshaw sofreram colisão traseira que resultou, como esperado, na danificação do tanque de combustível, provocando incêndio que matou Lily e submeteu Richard a diversas cirurgias. Richard recebeu US\$2.516.000,00 de danos compensatórios e US\$125.000.000,00 de danos punitivos. Os herdeiros de Lily receberam US\$559.680,00 de danos compensatórios. ${ }^{13}$ Finalmente, em maio de 1978 a Ford foi compelida a corrigir as falhas em 1,5 milhões de veículos.

O caso em tela representa a análise custo-benefício para a tomada de decisão. A decisão eficiente sob o ponto de vista puramente econômico seria o pagamento das indenizações. Já a eficiência sob o prisma jurídico consideraria o direito fundamental à vida e teria como eficiente a decisão de proceder-se ao recall.

São diversos os fatores que impulsionam a inércia do consumidor, transformando-a em verdadeira "indústria" da qual se valem os empresários. Dentre eles está o tratamento dado pelo Poder Judiciário a danos extrapatrimoniais. Tem sido cada vez mais comum ver decisões

\footnotetext{
${ }^{12}$ Disponível em: <http://www.engineering.com/Library/ArticlesPage/tabid/85/ArticleID/166/Ford-Pinto.aspx> Acesso em: 04/04/2018.

${ }^{13}$ Disponível em: <http://eticafordpinto.blogspot.com.br/> Acesso em: 04/04/2018.
} 
judiciais que consideram cobranças indevidas, constrangimentos públicos, venda casada, além de outras diversas violações ao consumidor, como meros aborrecimentos que não merecem a tutela estatal. Consumidores e advogados são vistos como oportunistas sob o argumento de que as decisões judiciais devem coibir a "indústria" do dano moral.

Enquanto os Tribunais continuarem tentando fazer prova do sofrimento, considerando como normais condutas abusivas e fixando indenizações com parâmetros equivocados, os empresários não terão o menor estímulo capaz de provocar a mudança de comportamento.

Outro fator que fomenta a "indústria" da inércia do consumidor é a falta de conhecimento mínimo jurídico por parte da população. A pesquisa do CNJ utilizada neste trabalho identificou que os serviços de água, luz, telefone e bancos representam a maior porcentagem de pessoas que vivenciaram conflitos e não procuraram solução por não saber que poderiam fazê-lo, conforme se vê no Gráfico 4 abaixo:

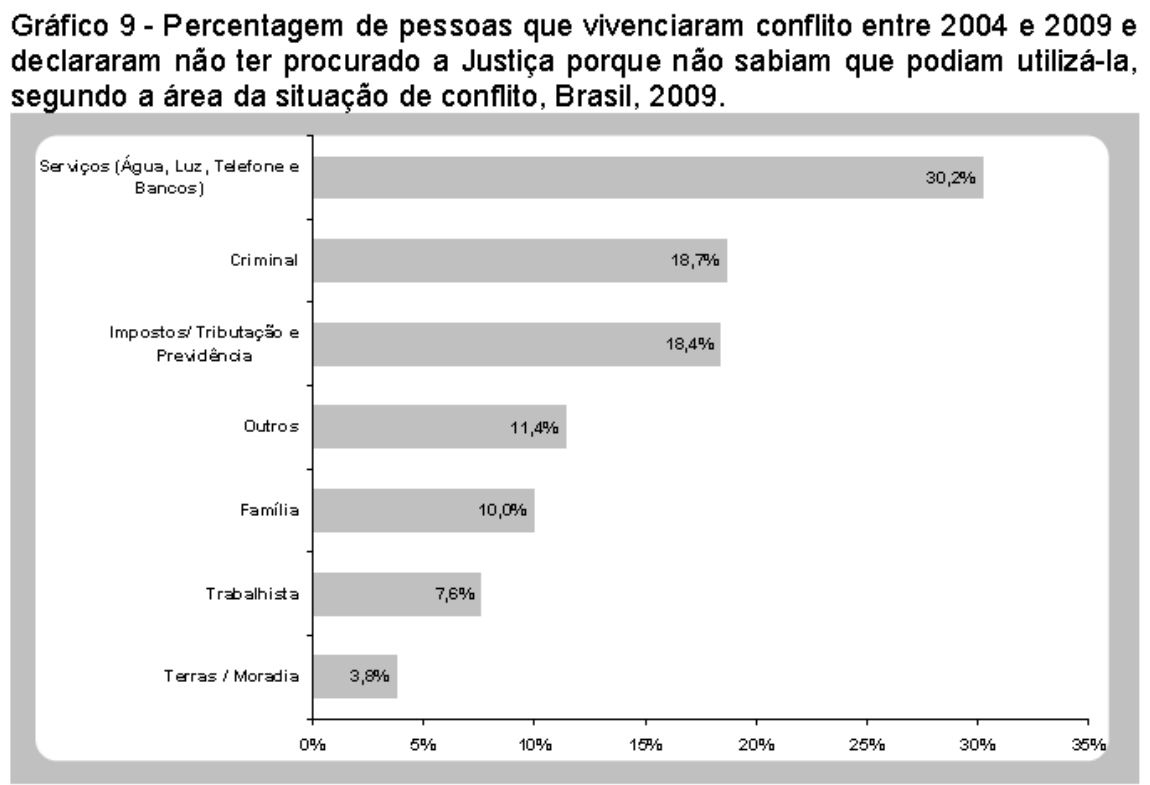

Fonte: CNJ.

De toda a população consultada, $6,8 \%$ das pessoas que afirmaram ter vivido conflitos deixaram de buscar solução por falta de conhecimento e, desse número, 30,2\% o tiveram nas relações de consumo, conforme apontado no Gráfico acima. Há, ainda, outros fatores relacionados ao acesso à justiça que fazem com que o consumidor fique inerte frente às violações praticadas pelos fornecedores. Como o objetivo deste trabalho não é exauri-los, mas apenas identificar a existência do que se chamou de "Indústria da Inércia do Consumidor", entende-se que os dados expostos confirmam do objeto da pesquisa. 
A proposta de solução para os conflitos consumeristas deve, pois, passar necessariamente pela consideração do Princípio da Eficiência Econômico-Social, na medida em que devem ser considerados os reflexos sociais das decisões tomadas pelo Poder Judiciário contra violadores contumazes dos direitos do consumidor. O mercado de consumo saudável deverá ser a consequência do desestímulo da prática de condutas lesivas resultantes de cálculos econométricos que consideram o comportamento do Judiciário e os demais elementos que contribuem para a inércia do consumidor, de modo que seja extinta essa tomada de decisão desconsideradora dos reais motivadores econômicos dos agentes em mercado (produtores e consumidores) transformando a reparação de danos em falácia que incentiva verdadeira "indústria” em desfavor das relações de consumo.

\section{CONCLUSÃO}

A localização "topográfica" da defesa do consumidor na CRFB/88 confere-lhe a característica de direito fundamental, conforme artigo $5^{\circ}$, XXXII, da Carta Maior, bem como, de Princípio da Ordem Constitucional Econômica, nos termos do seu inciso V do Art. 170.

A percepção de que o consumidor é parte vulnerável nas relações de consumo, dado o gigantismo das empresas, além da distância entre os contratantes, afastando a antiga concepção de acordo direto entre dois sujeitos, foi indispensável à inclusão do texto constitucional referenciado. Contudo, algumas questões são tão complexas que a simples estipulação legal não é suficiente para o seu controle. Há determinados casos em que é imprescindível a análise multidisciplinar e ampla, de forma a compreender o funcionamento dos bloqueios e estímulos necessários à efetivação dos direitos pretendidos.

A racionalidade econômica convoca à desconstrução da ilusão de que a tutela Constitucional do consumidor dar-se-á naturalmente. É preciso que os custos das transações sejam observados nas tomadas das decisões judiciais, as quais além de tudo, realocam riqueza. Ao resolver caso específico entre as partes, é ingênuo considerar que a solução direciona-se apenas aos litigantes. Indiretamente é enviada mensagem à sociedade sobre quais os comportamentos proibidos (judicialmente obstaculizados) ou aceitos (incentivados) e as suas consequências.

Dirigentes de empresas contumazes violadoras de direitos dos consumidores, ao perceberem decisões que consideram os danos como meros aborrecimentos, não terão o menor estímulo para a mudança de comportamento. Igualmente não se prestam a tal fim 
decisões que temem mais o "enriquecimento" do consumidor em detrimento do desestímulo da violação.

Não raras vezes, embora haja discurso de repúdio à prática lesiva, são aplicados valores irrisórios às indenizações. Isso se dá por profunda confusão sobre a verificação e medição dos danos morais. O artigo buscou colocar a "lente" da AED sobre o assunto, permitindo concluir que o comportamento judicial, somado aos diversos motivos que afastam as pessoas do Judiciário, tem criado verdadeira "indústria" da impunidade de nefastas e contumazes práticas comerciais. Nessa "indústria" os fatores de impulsão da produção passam a ser, exatamente, fonte de violações e da inércia dos consumidores. Obviamente não se esta propondo medidas jurídico-normativas extremas como as percebidas durante surgimento da teoria dos punitive damages nos EUA, com condenações milionárias. O que se propõe é o abandono da leitura simples das violações aos direitos dos consumidores.

Enquanto não se incorporar, nas decisões judiciais brasileiras, a visão proporcionada pela AED, empresas deixarão de aperfeiçoar a prestação dos seus serviços, minimizando os danos causados; haverá desalento jurisdicional, falta de confiança no Judiciário e tantos outros prejuízos tão caros a aqueles que são vulneráveis nesse tipo de relação: os consumidores.

\section{BIBLIOGRAFIA}

ANDRADE, André Gustavo Corrêa de. Dano Moral e Indenização Punitiva. Rio de Janeiro: Editora Forense, 2006.

BERNARDO, Wesley de Oliveira Louzada. Dano Moral: Critérios de fixação de valor. Rio de Janeiro: Editora Renovar, 2005.

CAVALIERI FILHO, Sérgio. Programa de Responsabilidade Civil. 6 ed. São Paulo: Malheiros Editores, 2005.

. Programa de direito do consumidor. São Paulo: Atlas, 2008.

COASE, Ronald H. The Problem of Social Cost. Law \& Econ, v. 3, p. 1-44, Oct. 1960. Disponível em: <http://www.econ.ucsb.edu/ tedb/Courses/UCSBpf/readings/coase.pdf> Acesso em: 04/04/2018.

Cultura Brasileira. Código de Hamurabi. Disponível em:

<http://www.cpihts.com/PDF/C\%C3\%B3digo\%20hamurabi.pdf> Acesso em: 04/04/2018.

DINIZ, Maria Helena. Curso de direito civil brasileiro. São Paulo: Saraiva, 2005.

2010.

Curso de direito civil brasileiro: Responsabilidade Civil. ed. 24. São Paulo: Saraiva,

DURKHEIM. Émile. As regras do método sociológico. São Paulo: Martins Fontes, 1995. 
FERRAZ JR, Tercio Sampaio. Introdução ao estudo do Direito. São Paulo: Atlas, 2003.

GILISSEN. John. Introdução histórica ao direito. Lisboa: Fundação Calouste Gulbenkian, 1979.

GONÇALVES, Carlos Roberto. Responsabilidade civil. São Paulo: Saraiva, 2005.

GONÇALVES, Everton das Neves e STELZER, Joana. O Direito e a Law and Economics: Possibilidade Interdisciplinar na Contemporânea Teoria Geral do Direito. In JURIS: Revista do Departamento de Ciências Jurídicas da FURG, Rio Grande, RS: Editora da FURG, v. 11, n. 1, 2005. Disponível em: <http://www.seer.furg.br/juris/article/view/595/138>. Acesso em: 04/04/2018.

O Direito e a Ciência Econômica: a possibilidade interdisciplinar na Contemporânea Teoria Geral do Direito. In Anais da XI Conferência Anual da Associação LatinoAmericana e do Caribe de Direito e Economia - ALACDE, Brasília, DF/ site da Berkeley University. v. 1, 2007, p. 1-11. Disponível em: <http://escholarship.org/uc/item/39q6m55k?query=everton>, Acesso em: 04/04/2018.

. O viés econômico do direito justo e eficiente: O princípio da eficiência econômicosocial. In OPUSZKA, Paulo Ricardo e SÉLLOS-KNOERR Viviane Coêlho (Orgs.), Revista Jurídica da Unicuritiba, v. 3, n. 32, 2013. p. 128-162. Disponível em:

<http://revista.unicuritiba.edu.br/index.php/RevJur/article/view/682>. Acesso em: 04/04/2018.

. O Princípio da Eficiência Econômico-Social no Direito Brasileiro: a tomada de decisão normativo-judicial. In Sequencia. v. 35, n. 68. Florianópolis, SC. 2014. p. 261-290. Disponível em: < https://periodicos.ufsc.br/index.php/sequencia/article/view/21777055.2013v35n68p261>. Acesso em 04/04/2018.

HICKS, John. The foundations of welfare economics. Economic Journal. London: Royal Economic Society, v. 49, n. 196, p. 696-712, 1939. Disponível em:

<http://www.jstor.org/stable/2225023>. Acesso em: 04/04/2018.

IHERING, Rudolf von. A luta pelo direito. São Paulo: Forense, 2006.

KALDOR, Nicholas. Welfare propositions in economics and interpersonal comparisons of utility. Economic Journal, London: Royal Economic Society, v. 49, n. 195, p. 549-552, 1939. Disponível em: 〈http://www.jstor.org/stable/2224835>. Acesso em: 04/04/2018.

PARETO, Vilfredo. Manuale di economía política con una introduzione ala scienza sociale. Milão, Società Editrice Libraria, 1909.

POSNER, Richard Allen. El análisis económico del derecho. México; trad. de Eduardo L. Suárez. 2. ed. México: Fundo de Cultura Econômica, 2007.

SANTOS, Antônio Jeová. Dano Moral Indenizável. 4. ed. São Paulo: Editora Revista dos Tribunais, 2003. 